\title{
O Público do Museu da Inconfidência: da legitimação do patrimônio nacional às necessidades de fruição para os turistas 1
}

\author{
The audience of the Inconfidencia Museum: the legitimacy of national \\ heritage to the needs of the tourist fruition
}

\author{
La audiencia del Museo de la Inconfidencia: la legitimidad del \\ patrimonio nacional a las necesidades de la fruición turística
}

Leandro Benedini Brusadin ${ }^{2}$

\begin{abstract}
Resumo: $O$ debate que trata do patrimônio cultural no Brasil se faz presente quanto às suas formas de preservação e quanto às suas ferramentas de identidade. Entretanto, torna-se necessário refletir as formas de apropriação de quem o faz existir: o público. Nesse trabalho, por meio de análise documental, ponderamos os índices de visitação do Museu da Inconfidência, em Ouro Preto, desde sua criação em 1944 até $\mathrm{o}$ ano de 2009. Tais indicadores quantitativos nos permitem afirmar que o público do Museu da Inconfidência foi quem legitimou a tradição nacionalista inventada no Governo de Getúlio Vargas e materializada em sua exposição. Nesse artigo ainda foram considerados os testemunhos dos visitantes, registrados no Livro de Ocorrências, os quais forneceram subsídios para analisar a visitação ao longo dos anos sob o âmbito do Turismo. Conclui-se que o Museu da Inconfidência teve que se adaptar às necessidades de fruição do turista contemporâneo, muito embora não pode se desvincular das raízes nacionalistas que lhe deram origem.
\end{abstract}

Palavras-chave: Patrimônio Cultural; Museu da Inconfidência; Público; Turismo.

Abstract: The debate which deals with cultural heritage in Brazil is present as its forms of preservation and as its tools of identity. However, it is necessary to reflect the forms of appropriation of who does it exist: the public. In this work, through documentary analysis, we considerated the contents of Inconfidencia Museum visitation, in Ouro Preto, since its inception in 1944 until 2009. Such quantitative indicators allow us to tell the public of the Inconfidencia Museum was who legitimated the nationalist tradition invented in the Government of Getúlio Vargas and materialized in its presentation. This article still were considered the visitors' testimonies, were recorded in the Book of Occurrences, which provide subsidies to analyze the visitation over the years under the scope of tourism. It is concluded that the Inconfidencia Museum had to adapt to the needs of contemporary tourist fruition, although it couldnot if unlink of nationalist roots that gave its origin.

1 Artigo oriundo de Tese de Doutorado defendida no Programa de Pós-Graduação em História da Universidade Estadual Paulista (UNESP) de Franca em outubro de 2011.

2 Graduado em Turismo pela Puc-Campinas, Mestre em Hospitalidade pela Universidade Anhembi-Morumbi (UAM) e Doutor em História pela Universidade Estadual Paulista (UNESP) de Franca. Professor Adjunto do Departamento de Turismo da Universidade Federal de Ouro Preto (UFOP). E-mail: leandro@turismo.ufop.br 
Key-Words: Cultural Heritage; Inconfidencia Museum ; Audience; Tourism.

Resumen: El debate que se ocupa de patrimonio cultural en Brasil encuentra presente como sus formas de preservación y como sus herramientas de identidad. Sin embargo, es necesario reflexionar las formas de apropiación del que existe: el público. En este trabajo, por medio de análisis documental, consideramos el contenido de la visitación del Museo de la Inconfidencia, en Ouro Preto, desde su creación en 1944 hasta 2009. Tales indicadores cuantitativos permiten decir el público del Museo de la Inconfidencia legitimara la tradición nacionalista inventado en el gobierno de Getúlio Vargas y materializado en su exposición. Todavía fueram considerados para em este artículo testimonios de los visitantes que se registraron en el Libro de Ocurrencias que concede subvenciones para analizar la visita durante los años en el ámbito del turismo. Se concluye que el Museo de la Inconfidencia tuve que adaptarse a las necesidades de la fruición del turismo contemporáneo, aunque no podría si desvincular de las raíces nacionalistas que le dio origen.

Palavras clave: Patrimonio cultural; Museu de la Inconfidencia; Audiencia; Turismo.

\section{INTRODUÇÃO}

Se Ouro Preto é um símbolo nacional, atraindo legiões de turistas que necessariamente a procuram, o Museu da Inconfidência se vangloria de possuir essa mesma condição. "A sua força de competição a esse respeito é de tal ordem que o índice de afluência da bilheteria há anos vem sendo utilizado como indicador de números de que diariamente faz crescer a população flutuante da antiga capital da região das Minas. O Museu da Inconfidência é porta de entrada privilegiada para Ouro Preto" (Mourão, 1995, p. 5). O Museu da Inconfidência é visto logo no acesso principal de Ouro Preto, na Praça Tiradentes, posto que em seu interior o turista encontra um retrospecto do que vai conhecer na caminhada pelas ruas e na contemplação das igrejas. O público ainda pode exercitar a imaginação ao avistar os demais monumentos e o casario dos séculos XVIII e XIX.

Os elementos expostos no Museu da Inconfidência (MI) são, também, permeados por uma trama política carregada de elementos ideológicos e simbólicos da sociedade que lhe deu origem e das diversas apropriações que se sucederam. A ideia de celebração da Conjuração Mineira propunha um movimento nacionalista e patrimonial. Fatores relacionados ao imaginário popular e o seu poder simbólico parecem ter sido as prerrogativas para essa criação, sendo que a visitação turística contemporânea viria acentuar a propagação destas concepções. Pressupõe-se que a representação instalada no $\mathrm{Ml}$ consiste em um jogo de símbolos que situam várias formas de interpretação. Lembramos que "um dos caracteres fundamentais do facto social é, precisamente, o seu aspecto simbólico. [...] Frequentemente, os comportamentos sociais não se dirigem tanto às coisas em si, mas aos símbolos destas coisas" (Baczko, 1985, p. 306).

Desde o primeiro momento de sua criação, a articulação entre os elementos de um passado construído com intencionalidade serviria a um presente em que a ideia de turismo cultural se apresenta como ferramenta de lazer cultural para muitos brasileiros e estrangeiros. 0 poder do símbolo também é fruto da análise de Bourdieu (2002, p. 8), que o conceitua "com efeito, esse poder invisível o qual só pode ser exercido com a cumplicidade daqueles que não 
querem saber que lhe estão sujeitos ou mesmo que o exercem." Utilizando essa perspectiva, podemos inserir os símbolos como instrumentos da integração social, na qual se percebe que o patrimônio legitimado pelo Estado pode conter uma função política que penetra no imaginário social inconscientemente.

Tendo em vista que a visitação ao Museu da Inconfidência também foi uma forma de disseminar as ideias que lhe foram atribuídas, verificamos a necessidade de estudar essa representatividade, em aspectos quantitativos, ao longo dos anos de funcionamento da Instituição. Para tanto, apresentamos e discutimos nesse artigo a visitação do Museu da Inconfidência, de 1945 a 2009, baseada em número de incidência. Esta periodização refere-se à possibilidade de analisar as principais transformações ocorridas no $\mathrm{Ml}$, de acordo com a quantidade de visitantes que estiveram na Instituição. Foram encontrados documentos, durante a pesquisa, nos arquivos administrativos da Casa do Pilar, os quais registram a visitação total, dividida no início entre homens, senhoras e crianças. A importância do levantamento serial destes números também se deve ao fato de o Inconfidência ser o único órgão a registrar os visitantes de Ouro Preto. Esses números podem servir para identificar a relação existente entre a movimentação turística e as ações direcionadas ao patrimônio cultural que fizeram parte da história do Museu da Inconfidência. Ressalta-se que este trabalho não analisa substancialmente a relação deste patrimônio com a comunidade local, pois este deve ser a razão de outras publicações.

O debate sobre os museus deve permear algo que algumas vezes fica ausente, mas para este artigo torna-se primordial: o público. Guarinello (1995) corrobora com isso ao afirmar que o público é o grande ausente de muitas análises e o historiador deve se sensibilizar com isso. 0 público é a alma do museu, histórico ou não. E se um museu histórico deve ser a interface entre o saber acadêmico e a população, não pode voltar-lhe as costas. Em contrapartida, Saliba (2007) relaciona que, de qualquer forma, devemos concordar que é necessário superar o projeto colecionista e antiquário em relação ao passado - mas a visão de mercado, que impregna a história de circulação massiva, e o turismo globalizado não estão, ambos, apenas a vestir com novas roupas essas mesmas concepções?

Diante de tais problematizações teóricas, pretende-se compreender a ótica dos turistas e a sua relação com o Museu da Inconfidência por meio da análise da visitação em suas exposições permanente e temporária, em aspectos quantitativos e qualitativos. As fontes impressas e manuscritas utilizadas para o estudo desse público foram recolhidas no arquivo administrativo da Casa do Pilar e alguns dados foram repassados pelo Setor de Difusão e Promoção Cultural do MI. As outras fontes utilizadas para estas análises são os boletins informativos do Museu da Inconfidência, denominados "Isto é Inconfidência", além de jornais mineiros da época em questão. Destacam-se, por fim, os testemunhos dos visitantes registrados no Livro de Ocorrências, de 1975 a 2009, encontrado no Arquivo da Secretaria do Museu, documento este que contém fatos vivenciados durante a visitação. 


\section{RETROSPECTO HISTÓRICO QUANTITATIVO DO PÚBLICO DO MUSEU DA INCONFIDÊNCIA}

Para o estudo quantitativo de público do Museu da Inconfidência, utilizamos alguns dados que foram coletados por um ex-funcionário da Instituição, João Crisóstomo Ribeiro, o qual tinha a função de registrar a quantidade de visitantes em algumas categorias. Posteriormente, o registro do público passou a ser tarefa do Setor de Difusão e Promoção Cultural. De acordo com a computação desses dados, pudemos elaborar a Tabela 1, que contém a visitação total desde 1945 até $o$ ano de 2009.

\begin{tabular}{cccccccc}
\multicolumn{7}{l}{ Tabela 1} & Visitantes do Museu da Inconfidência de 1945 a 2009 \\
\hline $\mathbf{1 9 4 5}$ & 12.281 & $\mathbf{1 9 6 1}$ & 84.077 & $\mathbf{1 9 7 7}$ & 101.033 & $\mathbf{1 9 9 3}$ & 105.873 \\
$\mathbf{1 9 4 6}$ & 12.442 & $\mathbf{1 9 6 2}$ & 84.683 & $\mathbf{1 9 7 8}$ & 140.601 & $\mathbf{1 9 9 4}$ & 186.509 \\
$\mathbf{1 9 4 7}$ & 9.741 & $\mathbf{1 9 6 3}$ & 74.305 & $\mathbf{1 9 7 9}$ & 120.515 & $\mathbf{1 9 9 5}$ & 149.806 \\
$\mathbf{1 9 4 8}$ & 9.503 & $\mathbf{1 9 6 4}$ & 71.893 & $\mathbf{1 9 8 0}$ & 122.103 & $\mathbf{1 9 9 6}$ & 131.405 \\
$\mathbf{1 9 4 9}$ & 10.060 & $\mathbf{1 9 6 5}$ & 75.846 & $\mathbf{1 9 8 1}$ & 132.006 & $\mathbf{1 9 9 7}$ & 109.345 \\
$\mathbf{1 9 5 0}$ & 12.143 & $\mathbf{1 9 6 6}$ & 90.337 & $\mathbf{1 9 8 2}$ & 124.398 & $\mathbf{1 9 9 8}$ & 126.925 \\
$\mathbf{1 9 5 1}$ & 13.095 & $\mathbf{1 9 6 7}$ & 101.072 & $\mathbf{1 9 8 3}$ & 138.660 & $\mathbf{1 9 9 9}$ & 119.826 \\
$\mathbf{1 9 5 2}$ & 14.926 & $\mathbf{1 9 6 8}$ & 133.119 & $\mathbf{1 9 8 4}$ & 122.972 & $\mathbf{2 0 0 0}$ & 100.945 \\
$\mathbf{1 9 5 3}$ & 22.434 & $\mathbf{1 9 6 9}$ & 124.846 & $\mathbf{1 9 8 5}$ & 141.952 & $\mathbf{2 0 0 1}$ & 101.358 \\
$\mathbf{1 9 5 4}$ & 29.018 & $\mathbf{1 9 7 0}$ & 146.469 & $\mathbf{1 9 8 6}$ & 175.370 & $\mathbf{2 0 0 2}$ & 105.855 \\
$\mathbf{1 9 5 5}$ & 27.583 & $\mathbf{1 9 7 1}$ & 151.236 & $\mathbf{1 9 8 7}$ & 139.976 & $\mathbf{2 0 0 3}$ & 93.156 \\
$\mathbf{1 9 5 6}$ & 27.325 & $\mathbf{1 9 7 2}$ & 153.089 & $\mathbf{1 9 8 8}$ & 130.855 & $\mathbf{2 0 0 4}$ & 94.606 \\
$\mathbf{1 9 5 7}$ & 35.549 & $\mathbf{1 9 7 3}$ & 146.469 & $\mathbf{1 9 8 9}$ & 142.941 & $\mathbf{2 0 0 5}$ & 92.507 \\
$\mathbf{1 9 5 8}$ & 41.226 & $\mathbf{1 9 7 4}$ & 103.453 & $\mathbf{1 9 9 0}$ & 118.399 & $\mathbf{2 0 0 6}$ & $59.488^{3}$ \\
$\mathbf{1 9 5 9}$ & 50.161 & $\mathbf{1 9 7 5}$ & 100.107 & $\mathbf{1 9 9 1}$ & 100.010 & $\mathbf{2 0 0 7}$ & 113.172 \\
$\mathbf{1 9 6 0}$ & 71.388 & $\mathbf{1 9 7 6}$ & 98.040 & $\mathbf{1 9 9 2}$ & 90.976 & $\mathbf{2 0 0 8}$ & 112.276 \\
& & & & & & $\mathbf{2 0 0 9}$ & 112.729 \\
\hline
\end{tabular}

Fonte: Museu da Inconfidência - Relatórios Anuais de Visitação (1945-1982) / Estatísticas do Setor de Difusão $(1983-2009)^{4}$

Diante deste quadro numérico, a primeira consideração que não pode deixar de ser mencionada é a capacidade desenvolvida pelo Museu da Inconfidência para atrair o público, principalmente se comparada a outras instituições do mesmo gênero no Brasil. Até o dia 31 de dezembro de 1945, pouco mais de um ano após sua inauguração, já havia passado pelo MI um público de 12281 visitantes, sendo 7085 homens, 3492 mulheres e 1704 crianças. Nos anos que se seguiriam, os números, de forma geral, subiram gradualmente, porém foi apenas após a construção da estrada de rodagem, durante o governo estadual de Juscelino Kubitschek (19511955), que o MI conseguiu ampliar significativamente seu público. Esse político mineiro também se utilizara de algumas apropriações simbólicas inseridas nesse patrimônio com intenções nacionalistas e populares. Exemplo disso ocorreu em 1953, quando Juscelino Kubitschek adquiriu

\footnotetext{
${ }^{3}$ No ano de 2006 o Museu se manteve fechado ao público desde 12/03 a 22/08 para a sua reformulação.

${ }^{4}$ Os dados encontrados no Arquivo Administrativo da Casa do Pilar restringem-se até o ano de 1982, sendo que os números dos anos seguintes foram repassados pelo Setor de Difusão e Promoção Cultural do Museu da Inconfidência.
} 
o Relógio de Algibeira de Tiradentes das mãos de particulares e, em seguida, doou-o ao Museu da Inconfidência.

No entanto, o Museu da Inconfidência passou por um longo período oculto, posto que a Instituição havia sido privada do convívio do poder que lhe dera origem. Ao se referir a histórias contadas por antigos funcionários sobre esse tempo de poucos visitantes e considerando a sua conjuntura grandiosa e a já mencionada capacidade de atrair o público, Mourão (1994, p. 62) narra a seguinte passagem pitoresca:

[...] apareciam tão pingadas as visitas que certo dia um guarda de sala, aproveitando o vazio da tarde rotineira para repousar atrás da cortina do Panteão, assustou com seus roncos a turistas desavisados.

Em um sentido estrito, é importante ressaltar que mesmo com a repercussão da inauguração do Museu da Inconfidência em 1944 juntamente com a preocupação simbólica da celebração da Inconfidência pelo governo Vargas, a quantidade de visitantes diminuiu logo após a inauguração, entre os anos de 1947 e 1948. Por outro lado, um fator perceptível nesses dados é que, mesmo no período em que o $\mathrm{MI}$ não obteve a mesma atenção e interesse do governo seguinte, após o ano de 1949, o número de visitantes voltou a aumentar. Isso indica que apesar da incipiência das estruturas física e humana desse período, o Inconfidência tornara-se objeto de visitação importante em Ouro Preto. Esse fato pode ser explicado pelo aumento do fluxo de turistas no país direcionados para conhecer a história e as tradições inventadas pelos nacionalistas e incorporadas por parcela da sociedade. Assim, muitos brasileiros passaram a ter um desejo antes inexistente: conhecer a história pátria e de seus heróis viajando a Ouro Preto. O Museu da Inconfidência tornar-se-ia uma das formas dessas representações por meio de uma prática moderna: o turismo.

Ao se referir aos museus históricos nos anos de 1960, Bittencourt (2005) revela que os acervos eram homogêneos e expressavam uma dada visão política: a inexorabilidade do Estadonação e de suas classes dominantes projetadas no tempo. Tratava-se de uma visão da história teoricamente baseada no historicismo e na história positivista. Nesse sentido, não houve, no Brasil, cruzamento de estudos de cultura popular com a História, somente caracterização de personagens relevantes e a representação de tais fatos nos museus mostrava um país em que as elites tradicionais e aristocratas formariam um grupo coeso e forte. Esta também seria uma das características presentes no $\mathrm{MI}$ ao reforçar os ideais de uma elite política e intelectual daquela época.

Adiante no tempo, nota-se, ainda, uma contradição, pois um dos anos em que a Instituição mais recebeu visitantes, conforme a Tabela 1, foi o de 1972, durante o período da ditadura militar caracterizado pela repressão, tendo em vista que a concepção construída da Inconfidência Mineira pregava liberdade. Desse modo, o caráter nacionalista da Conjuração Mineira também auxiliaria os militares, não interferindo no número do público do Museu. Naquele momento, essa história já 
fazia parte do imaginário social dos brasileiros e de muitos estrangeiros que visitavam o país. Uma das explicações possíveis para esse aumento de visitantes seria que Orlandino S. Fernandes, diretor do Museu de 1959 a 1973, buscou a inserção do público escolar e ainda confeccionara um guia para direcionar a visita. Percebemos que logo no início da gestão desse diretor, a quantidade de público aumenta, consideravelmente, se comparada com os anos da gestão anterior de Cônego Trindade de 1944 a 1959.

A partir de 1974, quando se iniciou a gestão do escritor Ruy Mourão, encontramos o registro de público estrangeiro. Nota-se que a quantidade de estrangeiros cresceu ao longo dos anos e a de brasileiros oscilou, destacando que nesse mesmo ano foram recebidos 3161 estrangeiros e, em 1982, o número atingiu 10908 visitantes. Apesar do aumento considerável desse período, anos depois, em 1998, quando o cálculo passou a ser realizado pelo Setor de Difusão, o número diminuiu significativamente para 4848 visitantes estrangeiros. Dois anos após a reformulação, em 2008, o Museu recebeu 3392 pessoas dessa natureza.

A partir desses dados, observamos a predominância de visitantes europeus, sobretudo franceses, italianos e os alemães. Verificamos também, com menor incidência, a visitação de turistas vindos do oriente - Japão e China - e de países africanos. Da América do Norte, o maior número são de canadenses. De um modo geral, nos meses de julho a setembro, o número de visitantes estrangeiros é maior em função das férias na Europa.

As correspondências direcionadas ao diretor do Serviço do Patrimônio Histórico e Artístico Nacional, Rodrigo M. F. de Andrade, demonstram a preocupação em repassar ao órgão federal a quantidade do público do Museu da Inconfidência. Um ofício ${ }^{5}$ enviado em 1‥ de janeiro de 1945 pelo primeiro diretor Cônego R. Trindade, fazia a seguinte afirmação: "Tenho o prazer de comunicar a V. S. que este Museu foi visitado em janeiro por novecentas - e - oitenta - e -cinco pessoas". Por esse documento, é possível situar a preocupação do Museu e do SPHAN com a quantidade do público, já que era interessante que essa Instituição Museológica se tornasse uma referência nacional por sua localização e pela temática da Inconfidência Mineira. Naqueles tempos, provavelmente, ainda não se pensava em um turismo com grande quantidade de pessoas, mas sim, em um público letrado que conseguisse decodificar a exposição do Museu das Inconfidência. $O$ documento também mostra a estreita relação representada desde o início entre o Ml e o órgão federal do patrimônio histórico e seus intelectuais.

O Museu da Inconfidência também recebia muitas personalidades consideradas "visitas ilustres", como exemplo, podemos mencionar o ano de 1947, quando foram registradas as visitas de Érico Veríssimo, dos Embaixadores da China e da "Checo-Eslováquia" e, o ano de 1948, quando o Museu da Inconfidência recebeu a visita do Embaixador da França, do Ministro da Guatemala, da escritora Rachel de Queiróz, dos Deputados Drs. Cristiano Machado e José Maria de Alkimin, e dos Príncipes, D. Pedro e D. Maria de La Espezanza e de outros. Essas visitas expressam o caráter simbólico que havia adquirido a Instituição e, principalmente, o seu respaldo político e oficial

\footnotetext{
${ }^{5} \mathrm{Ml}$ : Arquivo Administrativo - Casa do Pilar.
} 
desde o seu surgimento. Ainda hoje, o Museu da Inconfidência é utilizado como suporte aos políticos e personalidades que desejam destaque no cenário social, posto que palanques são montados em sua frente nos eventos realizados na Praça Tiradentes. Nesse contexto, destaca-se o feriado nacional de 21 de abril, quando a Praça chega a ser fechada para o uso exclusivo de autoridades e seus convidados. Em 2009, a então Ministra da Casa Civil Dilma Rousseff, na presença do Presidente Lula, utilizou as instalações do Museu e um palanque para lançar o Programa PAC (Programa de Aceleração do Crescimento) das Cidades Históricas. Essa seria uma forma de demonstração e apropriação desses ideais para a futura candidata obter força no cenário regional e nacional tal como realizado por políticos em outras épocas.

O noticiário mineiro sempre se preocupou em veicular o número dos visitantes do Inconfidência. Em 1o. de Junho de $1977^{6}$ (p. 5), o jornal Estado de Minas informava que "em 4 meses 35 mil turistas foram conhecer o Museu da Inconfidência" e, ressaltava que as mulheres superavam os homens em número de visitantes: "Comprovando o interesse crescente das mulheres pelas coisas da cultura, o seu número superou sensivelmente o dos homens". Essa fonte também destaca que a transferência momentânea do Festival de Inverno para Belo Horizonte (quando o evento era organizado pela Universidade Federal de Minas Gerais) não redundou em grande perda para o movimento turístico de Ouro Preto, tal como demonstraram as estatísticas do Museu da Inconfidência. Outra notícia de 17 de agosto de 1977 (s/p) do mesmo jornal destaca que "Ouro Preto parece ter condições de, com seus próprios recursos, incrementar o seu movimento turístico". Apesar de ser uma Instituição Federal, o Museu da Inconfidência se manteve atrelado à cidade de Ouro Preto a fim de desenvolver o seu patrimônio e incrementar a atividade turística. Afinal, a invenção da cidade e a criação do Museu enquanto local histórico brasileiro se convergem na mesma direção.

Em 29 de Janeiro de 1982, o jornal Estado de Minas (Caderno Turismo. s/p) ${ }^{7}$, colocava como manchete do caderno Turismo: "132 mil turistas visitam o Museu da Inconfidência", ressaltando o trabalho do seu diretor Ruy Mourão com o projeto de transformar o $\mathrm{Ml}$ em centro dinâmico de produção e animação cultural. O jornal ainda relata que o ingresso custava 50 cruzeiros e a entrada era gratuita para crianças e para caravanas escolares. A mesma fonte menciona que o levantamento dos dados foi realizado pelo Sr. João Crisóstomo Ribeiro, pertencente ao quadro de funcionários da administração do Museu e afirmava que esse levantamento realizado pelo $\mathrm{MI}$ era o melhor registro da movimentação turística de Ouro Preto, "graças ao cuidadoso trabalho de sua recepção, no sentido de anotar a procedência de todos os visitantes". Apesar desses registros, ainda verifica-se a carência de classificação dos visitantes, postulada entre excursionistas que não pernoitam em Ouro Preto e turistas que permanecem mais de um dia na cidade. Isso influencia no tempo de visitação no Museu da Inconfidência e sua consequente fruição pelos visitantes.

\footnotetext{
${ }^{6} \mathrm{Ml}$ : Arquivo Administrativo - Casa do Pilar.

${ }^{7} \mathrm{Ml}$ : Arquivo Administrativo - Casa do Pilar.
} 
No Museu da Inconfidência, a quantidade de ingressos gratuitos dedicados a estudantes e a dias exclusivos para esse fim tornava-se uma prerrogativa para a inclusão da comunidade e para projetos educacionais. A partir de 1997, foi adotado formulário especial para registro de estudantes, contendo local de procedência, número de alunos, escola e série. No mesmo ano, observamos a incidência maior de visitação de escolas locais, de Belo Horizonte e de cidades vizinhas. Verificamos, ainda, que nos meses de maio a julho deste ano foram recebidas algumas escolas particulares de São Paulo e Rio de Janeiro, geralmente devido aos trabalhos de pesquisa sobre a Inconfidência Mineira, os artistas e os artífices dos séculos XVIII e XIX. A presença dos estudantes sempre fora marcante entre o público do Museu da Inconfidência. No ano de 2009, por exemplo, a Instituição recebeu 53173 alunos de escolas. Assim como os demais visitantes, esse público se acentua nos meses de Janeiro, Junho, Julho e Outubro.

A abrangência do público do Museu da Inconfidência se justifica pelas proporções geográficas amplas, muito além de Minas Gerais, pois a Inconfidência Mineira refere-se a um contexto nacional. No entanto, também é preciso dizer que o $\mathrm{Ml}$ representa outra parte dessa história, a colonização portuguesa e a exploração do ouro. Por essas e outras vertentes, a Instituição não se situa apenas como um museu regional, mas toma proporções nacional e mundial.

Em edição do Isto é Inconfidência (No. 18, 2006, p. 8) é divulgado o aumento da visitação da exposição permanente após o projeto de reformulação ocorrido no ano de 2006, muito embora os aspectos quantitativos demonstram que em alguns anos nas décadas de 1970, 1980 e 1990 não foram superados. No entanto, podemos afirmar que houve um crescimento das atividades do Museu em outros dos seus espaços, tal como, no espaço cultural do Museu da Inconfidência, que envolve a Galeria Sala Manoel da Costa Athaíde (Exposições Temporárias) e o Auditório, ambos localizados no Anexo I. Como estes passam a registrar a visitação a partir do ano de 1990, verificase um incremento do público pela diversificação das atividades do MI.

A partir dessa mesma data, a Área de Promoção Cultural cria os Projetos Vídeo no Anexo e Vídeo Científico, além das promoções em lançamentos de livros, cd's, filmes e outros vídeos. Nesse período, durante o mês de julho, a Sala Manoel da Costa Athaíde e o Auditório eram cedidos para as atividades do Festival de Inverno, quando era organizado pela Universidade Federal de Minas Gerais. Nos dias que correm, o Museu realiza atividades em sintonia com o Festival de Inverno que passou a ser organizado pela Universidade Federal de Ouro Preto.

Seguindo essa trajetória de ampliar suas atividades, foi criado o Cineclube do Museu da Inconfidência, com o patrocínio da Caixa Econômica Federal. Essa atividade é realizada no Auditório e oferece uma programação de alto nível, procurando formar um público com condições de apreciar a produção cinematográfica e proporciona um acesso gratuito às sessões que contam com um explicador e coordenador de debates (Isto é Inconfidência, N. 24, 2009).

$\mathrm{Na}$ Tabela 2, seguem os dados da visitação desses eventos e das exposições temporárias. Observando esses dados, é possível afirmar que o MI conseguiu ampliar o seu público devido à 
variedade de suas atividades. De um modo geral, a formação de um complexo cultural no Museu, permitiu a diversificação do público por meio da programação realizada no Auditório e na Sala Manoel da Costa Athaíde. Nesses espaços, as variações numéricas de visitantes ao longo dos anos acabam sendo naturais, pois envolvem características de cada exposição temporária e, também, dos eventos festivos e comemorativos inerentes a algumas datas especiais.

Tabela 2 - Público do Auditório e Visitantes da Sala de Exposições Temporárias (1990 à 2009)

\begin{tabular}{lll}
\hline Ano & Auditório & Exposições Temporárias \\
\hline $\mathbf{1 9 9 0}$ & 4.311 & 1.370 \\
$\mathbf{1 9 9 1}$ & 5.999 & 2.952 \\
$\mathbf{1 9 9 2}$ & 5.014 & 2.754 \\
$\mathbf{1 9 9 3}$ & 8.035 & 3.490 \\
$\mathbf{1 9 9 4}$ & 2.982 & 3.037 \\
$\mathbf{1 9 9 5}$ & 5.310 & 2.872 \\
$\mathbf{1 9 9 6}$ & 5.358 & 2.568 \\
$\mathbf{1 9 9 7}$ & 2.875 & 2.695 \\
$\mathbf{1 9 9 8}$ & 4.640 & 4.718 \\
$\mathbf{1 9 9 9}$ & 5.495 & 3.378 \\
$\mathbf{2 0 0 0}$ & 1.216 & 1.423 \\
$\mathbf{2 0 0 1}$ & 1.184 & 0 \\
$\mathbf{2 0 0 2}$ & 1.353 & 1.146 \\
$\mathbf{2 0 0 3}$ & 1.586 & 4.795 \\
$\mathbf{2 0 0 4}$ & 5.634 & 4.685 \\
$\mathbf{2 0 0 5}$ & 5.546 & 3.270 \\
$\mathbf{2 0 0 6}$ & 0 & 9 \\
$\mathbf{2 0 0 7}$ & 13.139 & 5.448 \\
$\mathbf{2 0 0 8}$ & 9.750 & 7.347 \\
$\mathbf{2 0 0 9}$ & 6.000 & 3.891 \\
\hline Fonte: Ml - Arquivo Estatístico do Setor de Difusão e Promoção Cultural
\end{tabular}

Fonte: MI - Arquivo Estatístico do Setor de Difusão e Promoção Cultural

Ao verificar os índices quantitativos da Sala de Exposição Temporária (Tabela 2), podemos analisar que o Museu da Inconfidência buscou não somente a variação de suas atividades em um contexto moderno de museu, mas também ampliou os seus significados para a sociedade ao direcionar novas temáticas que vão muito além do contexto da Inconfidência Mineira.

Percebe-se nos registros da visitação, desde 1945, que podem se identificar os processos inerentes aos usos desse patrimônio cultural pelo turismo e sua relação com a atividade museológica. É preciso enfatizar que, naquele período inicial, muito embora existissem, os estudos de público dos museus não era prioridade dessas instituições. No entanto, no Museu da

8 A partir de agosto de 2000, com a reconstrução do prédio do Anexo II do Museu da Inconfidência, onde funcionam os escritórios técnicos e laboratórios, a Sala Manoel da Costa Athaíde interrompeu o programa de realização de exposições temporárias e foi utilizada como laboratório de restauro de papel e madeira e sala de computação para a Seção de Segurança e Serviços Gerais e Seção de Difusão do Acervo e Promoção Cultural. A Galeria retomou suas atividades regulares apenas em setembro de 2002, com a exposição "Instrumentos de Música", inaugurada no dia 28.

9 O Auditório e a Sala Manoel da Costa Athaíde ficaram fechados ao público para as obras do projeto de reformulação e também serviram para condicionamento da Reserva Técnica. 
Inconfidência, o registro quantitativo dos visitantes, mesmo com mudança de categorias e ausência de outras mais, sempre ocorreu. Concluímos que os números de visitação do $\mathrm{MI}$ ao longo dos seus anos se impuseram como uma maneira de sustentar períodos difíceis de sua gestão e, ainda, legitimaram uma história que conseguiu atender a vários anseios do patrimônio e aos interesses políticos.

No entanto, ainda existem muitas questões em discussão sobre os museus e o seu público. Como o público se apropria e representa sua relação com as instituições museológicas? Sobre os visitantes de museus brasileiros, sabe-se que são, majoritariamente, escolarizados, com renda acima da média da população, basicamente divididos entre um público oriundo das visitas escolares (cativo) e um público não escolar (famílias e grupos diversos). Para Luciana S. Koptcke (2005, p. 187) afirma que esse tipo de estudo "trata-se mais de uma sociologia da visita do que de uma sociologia do público, visto que os documentos pouco informam sobre o visitante dos museus". Dados insuficientes sobre o público do Museu da Inconfidência, referente à sociologia da visita, ao longo do tempo, tornaram a análise desse aspecto uma tarefa difícil para esta pesquisa, embora, em parte, possa ser realizada por meio do testemunho de alguns visitantes.

\subsection{Testemunhos dos visitantes no Museu da Inconfidência}

Os testemunhos encontrados no Livro de Ocorrências ${ }^{10}$ nos fornecem outros parâmetros de estudo além das variáveis quantitativas já apresentadas, pois muitos questionamentos ainda permeiam a análise no Museu da Inconfidência: os seus roteiros de visitação permitem um momento de lazer atrelado às noções de memória e cidadania? A visitação ao Museu não seria apenas um compromisso do turista para computar mais um local visitado em Ouro Preto? Qual seria o sentido simbólico atribuído a uma visita no Inconfidência? Estas indagações parecem não ter respostas únicas, posto que a dinâmica do patrimônio cultural passa a ser cada vez mais um usufruto social e, com isso, diversifica as possibilidades dos seus resultados. Os testemunhos de público do Museu da Inconfidência somente puderam ser analisados após 1975, pois não foram encontrados registros anteriores a essa data.

Pôr em pauta a análise do público ou visitante dos museus, nestes termos, remete à dimensão política dessa Instituição, convidando a observar as relações de força que se produzem em seu entorno e no seu interior, relativas à afirmação dos parâmetros que orientam tanto o processo de musealização na escolha das peças que compõem o acervo, quanto à narrativa privilegiada para a sua exposição.

As análises dos depoimentos dos visitantes ao longo dos anos de funcionamento do Museu da Inconfidência tornam-se, a partir disso, uma ferramenta para refletir este processo e identificar as possibilidades de interpretação e educação por meio do turismo cultural na Instituição. Mesmo que as fontes, ainda hoje encontradas nos arquivos do Museu da Inconfidência, não configurem

\footnotetext{
${ }^{10}$ Museu da Inconfidência: Arquivo da Secretaria.
} 
um corpo documental capaz de dar suporte necessário para que sejam feitas generalizações mais consistentes, ainda assim, revelam-se importantes pelos indícios que trazem e que podem complementar os trabalhos antes apresentados.

Nos testemunhos recolhidos do Livro de Ocorrências, foram registrados, desde 1975, reclamações, elogios e sugestões dos visitantes que se importaram em se posicionar após a visitação na exposição permanente. Assim consta no documento: “O Livro de 'Queixas e Reclamações', contendo 100 (cem) folhas numeradas, e que é entregue à Portaria nesta data. Ouro Preto, 26 de março de 1975" (Rui Mourão - Diretor, Folha 1 - verso). Apesar da denominação atribuída ao documento, ressalta-se o fato de o livro registrar momentos da visitação que vão além das queixas e reclamações, pois também se encontram elogios e sugestões para o desenvolvimento do $\mathrm{Ml}$ sob a perspectiva dos que se propuseram a registrar o seu depoimento.

Ao examinar o documento, em um primeiro momento, fica nítido que um grande número de queixas é dedicado à proibição de fotografar o acervo. Isso demonstra a essência material que a fotografia confere à visita ao Museu da Inconfidência, ou seja, a sensação de aprendizado e / ou a fruição do atrativo cultural não bastam aos seus visitantes. O primeiro registro de um visitante já afirmava: "Para uma cidade de turismo, as medidas repressivas aos visitantes portadores de máquinas fotográficas é uma característica de subdesenvolvimento, não encontrada na mais insignificante cidade europeia" (M. A. D. W., 28/03/1975, Folha: 1). Mesmo nesse período, a fotografia já se tornara a forma mais concreta de materializar a visita a um atrativo cultural. Isso provavelmente ocorre devido ao fato de que o registro fotográfico possa permanecer por tempo indeterminado na memória social e, além disso, a veiculação das fotos para conhecidos evidenciariam com mais concretude os momentos de lazer cultural vivenciados naquele espaço museal.

Apesar disso, a segurança e a proteção do acervo parece ter sido sempre uma preocupação da Instituição, pois além de máquinas fotográficas, a proibição de utilizar bolsas, reclamada por alguns usuários nos anos de 1975, 1976 e, ainda em 1997, seria uma das formas de garantir que objetos do acervo não fossem roubados ou danificados. Entre essas passagens, encontra-se uma ocorrência em que o visitante menciona a sua insatisfação quanto à impossibilidade de utilizar carteira de mão. "Turismo arcaico, onde o visitante é tratado, a priori, como 'ladrão'. Os idealizadores do sistema aproveitariam bem se fizessem uma visita ao 'Louvre', Versalles, etc. Concordo com a proibição de fotos, mas bolsas tomadas na entrada do museu, nunca. Seria melhor a colocação de guardas nos recintos visitados" (sem nome, 09/07/1975, Folha: 2 - verso). Percebe-se, nesse testemunho, que os visitantes do Museu da Inconfidência daquele período possuíam referenciais de países europeus, mesmo porque esse era o público almejado pelos agentes do patrimônio.

A comparação com outros locais fora do país é realizada em outro testemunho. Além do mais, esse visitante relaciona a pobreza mental à impossibilidade de fotografar e ainda solicita uma visão mais administrativa do Museu da Inconfidência em relação ao turismo, do qual se considera cliente: 
Sr. Diretor, a pobreza da população de Ouro Preto é chocante! Mas a pior pobreza é a mental. Sou professor doutor em mercadologia e, como tal, fico triste com a proibição de fotografar, neste museu e nas igrejas de Ouro Preto. Perde-se, assim, um grande instrumento de divulgação, com o que o turismo fica sempre pequeno, limitado. Conheço Veneza, na Itália. Ouro Preto nada perde para ela. No entanto, Veneza (e sua gente!) arrecada com o turismo pelo menos um milhar de vezes o que obtém Ouro Preto. Lá, pede-se "pelo Amor de Deus" que se fotografe. Mas, a maior perda é a insatisfação do visitante. Um cliente insatisfeito faz perder ao menos dez clientes. Quando se pergunta, duas são as alegações para o crime de lesa pátria que aqui se faz. Primeiro, são os flashes. Ora, que se proíbam os flashes, não as fotos. Segundo,fala-se da segurança. Pense um pouco - 3 segundos devem bastar! - quem desejar fotografar com propósitos escusos o fará com uma câmera não diferente desta caneta com que escrevo! Senhor, a pobreza - mental, sobretudo - não pode prevalecer. Do jeito que está, Ouro Preto é um conjunto de pobres sentados em uma imensa riqueza! Atenciosamente, (rubica Ph.D, sem data, Folha: 38).

Em contrapartida às queixas que situavam as deficiências culturais do $\mathrm{Ml}$ comparadas a outras instituições da mesma espécie no exterior, são registradas, nesse mesmo livro, reclamações quanto à cobrança de ingressos por parte do Museu da Inconfidência. A iniciativa da cobrança, iniciada no início da gestão de Ruy Mourão, causara desconforto para alguns visitantes já em 1975, provavelmente não acostumados ao pagamento de atividades culturais no Brasil. Poderíamos supor que muitos turistas brasileiros direcionavam os seus gastos com outros elementos de uma viagem, tais como, hospedagem e alimentação, além de souvenires e compras em lojas, em detrimento da entrada dos atrativos culturais.

A cobrança do ingresso também é contestada em vários momentos pelos estudantes que solicitam diminuir o seu preço, e muitos outros pedem para cobrar somente $50 \%$ de seu valor total de acordo com os aspectos legais.

Por outro lado, o comportamento dos estudantes foi motivo de preocupação para uma visitante, mesmo considerando que a mesma tenha sido cativada pela exposição: “Ao receber grupos de estudantes, os responsáveis pelo mesmo (professores) deveriam se responsabilizar pelo silêncio e atitudes de seus educandos. Com certeza essa providência tornará a visita dos demais mais agradável e proveitosa. Atenciosamente, R M. V. P.S.: Parabéns pela disposição e pelas obras expostas". (sem data, Folha: 32) Nesse sentido, percebemos que muitos estudantes que visitavam a Instituição apenas estavam cumprindo uma parte dos requisitos da viagem a Ouro Preto e, talvez, por isso, o seu comportamento era indesejável para outros visitantes que buscavam fruir diante dos objetos expostos.

Na década de 1970, muitas reclamações foram direcionadas aos vigilantes e funcionários, requerendo maior atenção com o acervo, com a educação e o profissionalismo. No entanto, outros usuários registraram o seu testemunho elogiando a limpeza e a organização do Museu 
nesse mesmo período. "Perfeita, pode-se dizer da organização e distribuição das peças. É motivo de orgulho para todo brasileiro ter parte de sua história, a mais valiosa, a mais brasileira história da Nação, sintetizada neste Museu. Pergunto: Por que não editar uma obra com ilustração das peças e sua história, em belo volume, para completar a grande realização que é o Museu da Inconfidência?" (sem nome, 1975, Folha: 2 - verso). Essa última cobrança também viria de outro visitante ao relacionar a necessidade de exibição de áudios-visuais da História e do Acervo: "Por que não editar um guia do museu - de preferência com uma versão para uma língua estrangeira? Por que não aprimorar a organização do acervo? Idem à exibição contínua de uma áudio- visual sobre o ciclo do ouro ou o barroco mineiro? (...) (rubrica, 27/8/1982, Folha 8 - verso) Muitos desses aspectos viriam a ser atendidos com várias publicações editadas pelo $\mathrm{Ml}$ e pela inclusão tecnológica e multimídia em seu acervo após a reformulação de 2006.

O valor histórico dos objetos, ressaltado por visitantes como marcantes da memória nacional, fora motivo para muitos registros que situam a necessidade de isolamento e proteção das peças. Um visitante chega a situar a necessidade de que os "autos da devassa adquiridos da Inglaterra em 1980 fossem fotografados para serem expostos e os originais guardados" (sem nome, 28/7/1985, Folha: 8). Percebe-se, neste caso, que o valor histórico das peças do Museu passara a se sobrepor à própria exposição em si enquanto documento \monumento.

As queixas em relação à preservação do acervo continuariam quando foram registradas ocorrências que apontavam a má restauração e catalogação das peças e a destruição do acervo. Foi identificada, ainda, a falta de segurança e de proteção do acervo e a possibilidade de implementação de um sistema de ambientação (luz e temperatura). É registrada uma ocorrência, provavelmente no ano de 1998, de "várias crianças pulando em cima dos túmulos dos inconfidentes. Achei absurdo. Falta de respeito à nossa história. Assim, gostaria que fosse colocada fita ou qualquer outro tipo de obstáculo, para que isso não ocorresse. Obrigada." (E. R., sem data, Folha: 18). Como a presença de crianças sempre fora intensa no Museu, um usuário sugere uma forma de atendimento especial para esse público. Apesar disso, a perspectiva de introduzir as crianças na visitação do $\mathrm{Ml}$ era vista como uma maneira de formar cidadãos conscientes da história nacional reproduzida naquele espaço.

No que tange a tentativa de fornecer mais segurança ao acervo, um visitante foi colocado "para fora, passando a maior vergonha perante muitos turistas" por encostar a mão em uma das peças (sem nome, 13/06/1998, Folha 18 - verso). Esse mesmo visitante colocou no registro uma sugestão de colocar uma "placa na entrada orientando que matéria orgânica e bactérias das mãos aceleram o desgaste da peça". É importante levar em conta que o contato humano com as peças expostas se revela, aqui, como uma forma de ter um contato real com aquele processo histórico. Desse modo, os sentidos humanos não podem ser descartados como forma de interpretação do patrimônio cultural.

Diante dessa problemática, um testemunho bastante enfático também encontrado no Livro de Ocorrências é de uma professora do Curso de Turismo da Universidade Federal de 
Pernambuco (UFPE), a qual se preocupava com o comportamento dos turistas, delegando que este cuidado deveria ser tomado pelos seguranças.

Prezado (a) Senhor (a), Como brasileira consciente, professora do curso de turismo da UFPE e turista hoje neste pedaço extremamente importante do Brasil, venho colocar uma observação, sugestão e meu sentimento de revolta por ver/presenciar ações de turistas contra este patrimônio. Somente no andar térreo, presenciei pessoas tocando nos objetos sem que os vigilantes falassem contra no momento. Um homem tocou, fazendo barulho alto na carruagem (ele queria sentir se era madeira) e uma criança derrubou um objeto de metal pequeno (não sei dizer o nome). Fico imensamente triste de presenciar tais fatos pois, tanto os vigilantes estavam desatentos quanto pessoas sem educação continuam destruindo parte de nossa história e passado. Gostaria de sugerir treinamento para os vigilantes, com rodízios de salas e funções (experiência que vivenciei na Inglaterra enquanto fazia doutorado). Espero contribuir para que gerações futuras também possam usufruir e aprender sobre nossa história durante visitação nesta bela e rica cidade. Obrigada N. S. Recife, PE (21/10/2003, Folha: 49 - verso)

Essa discussão foi amenizada quando, em 2006, por ocasião da reformulação, foram inseridas proteções de vidro em grande parte das peças de seu acervo permanente. $O$ intuito sensitivo do "tocar" para o sentir do visitante passa a ser realizado nas máquinas de áudios-visuais implementadas. Ao tratar da reformulação do Museu da Inconfidência em seu livro, Rui Mourão (2008), que representa o próprio personagem de diretor do Museu, questiona as relações entre o tempo presente e o passado no Inconfidência. É narrada a preocupação em conhecer os seus visitantes, inclusive, a possibilidade de um programa de entrevista com a população de Ouro Preto. Nesse momento do drama, o diretor também menciona a regulamentação do ingresso pago. $\mathrm{O}$ autor relata que ninguém se opunha a cobrar do estrangeiro, mas se opunha a cobrar dos brasileiros. Para o diretor-personagem, o dinheiro cobrado dos ingressos se justificava à medida que seria aplicado na conservação das peças e para torná-las mais conhecidas, gerando efeito civilizador dentro da sociedade.

No entanto, essas e outras problemáticas na exposição permanente continuariam ocorrer durante os anos analisados. A falta de explicação das obras e a cobrança de ingresso foram registradas no seguinte testemunho:

Para Dr. Rui Mourão:

1. Por gentileza, sugiro que haja maiores detalhes e explicações sobre as peças expostas: mais detalhes acerca do autor, época, condições de execução, pormenores mais explícitas e pormenorizadas, perto de cada objeto.

2. Acho absurdo cobrança de ingresso como desestímulo à nossa população de renda tão baixa e tão carente de cultura. (serei ouvida, neste mutismo e indiferença nacional?) Obrigada! (R. B. A., 1981, Folha: 7 - verso).

Além dessa questão, outro testemunho registra preocupação em relação ao aspecto 
comunicativo com os visitantes estrangeiros: "Que se dê treinamento em línguas (inglês e espanhol) para os funcionários. Legendas de peças em 3 idiomas: português, inglês e espanhol)" (R.C., 2/7/2000, Folha: 30). Em outra passagem deixada por estudantes de Turismo, nota-se a mesma preocupação, além da necessidade de mapas. "Caros Senhores, nós, estudantes de Turismo, ficamos insatisfeitas por não haver placas informativas bilíngues e pessoas que possam nos passar informações importantes desse Museu. Agradecemos a vossa atenção. Pedimos também algum mapa ou guia sobre o museu". (R. e M., 01/05/2003, Folha: 45 - verso) Nesse sentido, foi enfatizada a preocupação com cada tipo de público e sua interação com a exposição do Inconfidência.

A inquietação com a História foi relacionada por outros visitantes do Museu da Inconfidência, já que possíveis erros históricos estariam sendo cometidos. Além de alguns usuários solicitarem maiores informações sobre autores, épocas e condições de execução das obras, em um vocabulário mais acessível, também é relatada a preocupação com o prédio: "a perfuração na parede para ponto de luz" e uma "porta do século XVIII com fechadura de hoje". (F. S, 24/07/86, Folha: 9) .

Foi com espanto que ao visitar o museu constatei a falta de segurança para com o acervo, a má restauração e catalogação das peças; é um absurdo o mobiliário antigo ser utilizado na entrada do museu para guardar pertences ou servir como balcão. Deveriam ser ministrados cursos de história aos guias do museu, devido o seu despreparo. Por favor, preservem o patrimônio histórico e cultural da melhor maneira possível (K. S., 24/07/1986, Folha: 9).

A ideia de conciliar o estudo e divertimento sempre fora o motivo de visita de escolas que buscam relacionar a visita ao $\mathrm{MI}$ com o conhecimento histórico, enquanto processo didático, e com o turismo, enquanto possibilidade de lazer cultural.

Quanto ao conteúdo das informações referentes ao acervo do Museu da Inconfidência, houve registro de visitantes que solicitaram guias treinados para contextualizar os objetos, oferecendo curso de História aos mesmos. Outra opção recomendada foi utilizar estudantes de História para este fim. No ano de 1998, outro testemunho é bastante enfático nesta questão:

Sr. Diretor do Museu da Inconfidência, estivemos aqui no dia 06 de setembro de 1998 e ao entrarmos, fomos abordados grosseiramente, por um dos guardas do acervo, primeira sala de exposição, que sem nenhuma gentileza, alertou um dos membros do nosso grupo, do deslize em tocar em uma das peças. Agora, às 16:00h desse mesmo dia, vimos à nossa frente, vários guias de turismo, sentados, sobre a tampa da arca, que se encontra na sala da entrada principal. Acreditamos que a falta de treinamento do pessoal contribui para o desrespeito em relação ao visitante e consequentemente à destruição do acervo tão mal protegido a nível de conservação. Esperamos que haja da parte dessa direção maior atenção a esse Museu. Obrigada, (Grupo de Salvador, 06/09/98, Folha: 18). 
Desse modo, os elogios e as reclamações seguiram essa direção no Livro de Ocorrência, visto que os aspectos mencionados acima se repetem ao longo do tempo. Em outro documento, nos boletins informativos Isto é Inconfidência, existe uma coluna denominada "O que disseram de nós", na qual o Museu seleciona alguns testemunhos de seus visitantes. Dentre as concepções que destacam o MI como patrimônio da nacionalidade brasileira, encontram-se passagens que registram a sua reformulação: "O museu, pós-reforma, está lindo! A iluminação e a disposição das peças estão bonitas!" (M. G. - BH em Isto é Inconfidência, no. 19, 2007, p. 7). No entanto, nesse mesmo boletim ainda são manifestados problemas com a linguagem e comunicação do Museu: "Muy lindo el museo y muy enteressante poder conecer La historia de Latinoamérica. Como entegrantes del Mercosur, nos gostaria de los explicaciones esten tambén en castellano (o espanõl) ya que está solo em português y en inglês. Um saludo argentino ilegible."

Se preocupação com a língua já tinha sido motivo de registro no Livro de Ocorrências em testemunhos anteriores, ao menos a legenda em inglês do acervo foi suprida após a reformulação

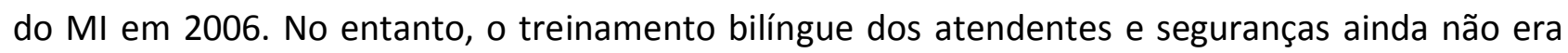
uma realidade em 2010 .

Outra questão surgiu após a reformulação do Museu: o problema identitário. Afinal, muitos visitantes estavam acostumados com a forma de expressão museográfica anterior. A preocupação com o conteúdo do $\mathrm{Ml}$ e sua relação com a mineiridade é expressa no testemunho de uma visitante no livro de ocorrências: "Sou moradora de Brasília e natural de Belo Horizonte. Conheço a cidade desde menina (hoje com 32 anos) não reconheço mais o museu como o Museu dos Inconfidentes. Na verdade não se vê mais nada da história (diga-se rica história) mineira neste museu". (D. N., 28/06/2008, Folha: 90 - verso). Outro usuário chega a registrar que deveria ter uma sala única para a Inconfidência Mineira, o que indica que o mesmo não relacionou o Panteão a este fato e a carência de mais objetos oriundos do movimento ainda se faz presente.

Em contrapartida, outra visitante faz uma analogia entre a reformulação do Museu da Inconfidência e a sua possibilidade maior de aprendizado. A seguinte passagem é registrada no Livro de Ocorrências: "Agradeço pelo prazer e por tudo que aprendi no Museu, completamente diferente do que vi em minha visita anterior. Um elogio especial ao segurança Gilberto, que com sua amabilidade e conhecimento, deu-nos uma aula de conhecimento prazeroso. Sugerimos que uma pessoa (ou mais) como ele possam ajudar os visitantes, pois é muito mais interessante que tocar computador". (V. S. C. P., 08/08/2008, Folha: 93)

O que se percebe é que mesmo após a reformulação do Museu da Inconfidência, em 2006, continuavam a ser registradas ocorrências negativas em relação ao atendimento, valores dos ingressos, proibição de fotografar, ausência de guias treinados, mal comportamento de alguns visitantes, principalmente escolares, necessidade de outras línguas, sinalização precária e falta de indicação em algumas obras, além da manutenção do prédio, inclusive de um certo ambiente sombrio. Insere-se ainda uma passagem em que usuário diz que o museu deveria ensinar os seus visitantes como se comportar. Ao que pensamos, o Ml deveria criar mecanismos interpretativos 
que permitissem ao visitante problematizar o pressuposto histórico ali exposto bem como lidar com o desafio de atendimento a um turista exigente diante das práticas de mercado.

Dessa forma, um fator inerente à movimentação turística que, muitas vezes, gera desconforto é o excesso de visitantes em um local. No caso do Museu da Inconfidência, o grande número de estudantes fora motivo de queixa por uma turista carioca: "Acho essencial a presença dos estudantes num museu histórico de tamanha importância como este, mas é impossível que os visitantes consigam aproveitar as informações. Não consigo fazer uma visita tranqüila diante de tanta movimentação de pessoas." (T. M. - Rio de Janeiro em Isto é Inconfidência, no. 19, 2007, p. 7). Ressaltamos o fato de que não basta o MI inserir grande número de estudantes em seu interior sem a construção de um roteiro específico que atenda os anseios de cada fatia escolar e suas necessidades para um turismo cultural prazeroso e educativo.

Os funcionários do Museu da Inconfidência são, em grande parte, representados pelos seguranças que estão presentes aos olhos dos visitantes na recepção e durante a visitação. Ao percorrer a exposição museológica do $\mathrm{MI}$, é possível observar a segurança realizada em cada sala. Os seguranças representam algo além da proteção do acervo e das pessoas que estão no edifício, posto que também repassam informações sobre a exposição museológica. Eles são orientados a ler as explicações de cada objeto museal quando a sala está vazia. Uma visitante registrou o trabalho esses profissionais, porém, mais uma vez, há a queixa do preço: “Os funcionários são solícitos e atenciosos. Por fim, parabenizo pela reforma. É necessário salientar ainda a acessibilidade do preço." (A. C. Z., Isto é Inconfidência, N. 24, p. 7).

Quanto ao livro de ocorrências, fica evidente que os testemunhos registram mais as queixas do que os elogios, haja vista o entendimento do seu próprio fim pelos visitantes. Algumas reclamações registradas foram supridas após a inauguração da Loja e Café e da comercialização de folhetos, livros e vídeos sobre o Museu da Inconfidência, além da instalação de computadores, oferecimento de áudio-guias e material informativo e ilustrado.

Percebe-se que os diferentes públicos que visitam o MI tendem a ser contemplados pelos programas educacionais, culturais e lúdicos de suas exposições. Apesar disso, o diretor, Ruy Mourão, em uma entrevista ${ }^{11}$ faz o seguinte relato: "o museu é o seguinte, o turismo ali varia né. Há sujeito ali que entram só porque precisam de conhecer o que tá lá dentro, e eles fazem uma visita rápida e coisa e saem, outros são mais demorados, os que interessam realmente, têm cabeça, têm cultura, às vezes ficam demoradamente dentro do museu". Mesmo diante das dificuldades de lidar com os diferentes públicos no Museu da Inconfidência, consideramos que a perspectiva de seleção de um público tido como erudito em detrimento de um público mais amplo não serve mais para a reutilização do patrimônio cultural para o Turismo, posto que a reconstrução histórica, por meio dos recursos museográficos, deve atender aos anseios dos seus diversos públicos e de suas possíveis apropriações.

\footnotetext{
${ }^{11}$ Entrevista realizada em 01/06/2010 transcrita e autorizada pelo depoente.
} 


\section{CONSIDERAÇÕES FINAIS}

Dentre os diversos elementos situados na exposição do Museu da Inconfidência, a contemplação dos personagens simbólicos situados no Panteão e das traves da forca de Tiradentes parece ser de mais fácil compreensão, posto que já fazem parte do imaginário social de quem visita o local. Os fatores nacionalistas criados no Governo de Getúlio Vargas foram legitimados pelo público do Museu da Inconfidência ao longo dos seus anos de sua história. No entanto, esse mesmo público requer diálogo com os diversos atributos turísticos e museológicos para a fruição desse patrimônio cultural brasileiro.

Apesar da indicação de algumas diretrizes passíveis de interlocução entre o campo da História e do Turismo, o Museu da Inconfidência se desenvolveu em seu campo museológico ao reformular a sua exposição permanente, incluindo importantes elementos tecnológicos e de entretenimento que convergem para as necessidades do público dos museus deste tempo. Além do mais, ainda é importante destacar a variedade de suas atividades, tais como, as exposições temporárias, Cine Clube do Inconfidência e outros eventos que seguem a conjuntura de uma cidade como Ouro Preto e de seus visitantes.

Fica perceptível, por meios dos dados quantitativos e testemunhos registrados, que os visitantes do Museu da Inconfidência não buscam apenas conhecer a história nacional, mas sim, um diálogo com o presente por meio de ferramentas que permitem uma fruição que atrela conhecimento ao lazer por meio do turismo cultural. Para tanto, aspectos relacionados a fatores comerciais da contemporaneidade se alinham ao passado representado no acervo. Dessa forma, o conhecimento histórico e a atividade turística tornam-se práticas que não são separadas pelo público dos museus. Esse é o diálogo que um museu histórico pode mediar de uma forma interdisciplinar. Ao refletir o ato de visitação de um turista em um museu histórico, inserimos a fórmula de Mirabeau, lembrada por Baczko (1985), que resume essa dupla tendência: não basta mostrar ao homem a verdade; a questão capital é levá-lo a apaixonar-se por ela; não basta servi-lo nas suas exigências primárias, se não apoderarmos de sua imaginação.

Ao relacionar as ações atuais de um museu histórico, como estas premissas seriam alcançadas? A ideia defendida aqui é que ainda não existe um tratamento integrado entre os campos que envolvem esse processo e propomos uma reutilização do patrimônio cultural que atenda às necessidades do presente em um processo constante de reconstrução do passado. Em uma concepção de interpretação educativa, avaliamos a possibilidade de mediar uma posição de turistas meramente consumistas e levianos para educandos e interpretes do patrimônio. Para isso, além de propostas humanizadoras de viagens, é preciso que as instituições culturais permitam a fruição de uma interpretação livre e problematizadora. Não podem estar ausentes neste debate as apropriações das tradições, o poder simbólico e o imaginário social, sendo que o processo de memória também implica nos resultados das relações entre o Turismo, a História e a Museologia. Ao inserir as reflexões teóricas juntamente com as formas de interpretação do patrimônio, 
buscamos ir além de uma indicação tecnicista de utilização dos bens culturais, atingindo uma visão complexa e dinâmica do patrimônio e de seus tempos. Devemos reconhecer que o museu pode transformar-se em um instrumento para problematizar as identidades e ainda ser um mecanismo de constante reconstrução histórica dos símbolos no imaginário social. Para tanto, o uso adequado desse espaço é constituído por uma visão de viajar relacionada ao lazer em sintonia com o aprendizado.

\section{REFERÊNCIAS}

Baczko, B. (1985). Imaginação social. Enciclopédia Einaudi. Lisboa: Imprensa Nacional Casa da Moeda, v.5, pp. $296-378$.

Bittencourt, J. N. (2005). Receita para a refeição cotidiana dos museus. In: CHAGAS, Mario (Org.). Museus: antropofagia da memória e do patrimônio. Revista do Patrimônio Histórico e Artístico Nacional, n. 31.

Bourdieu, P. (2002). O poder simbólico. Rio de Janeiro: Bertrand Brasil.

Estado de Minas, Belo Horizonte (MG), 1/06/1977, 17/08/1977, 29/01/1982.

Guarinello, N. L. (1995). Comentário IX. Anais do Museu Paulista. História e Cultura Material. São Paulo: Universidade de São Paulo, jan. /dez., v . 3.

Isto é Inconfidência. Boletins Informativos. Ministério da Cultura. Instituto do Patrimônio Histórico e Artístico Nacional. Ouro Preto: Museu da Inconfidência, n. 18/19/24.

Koptcke, L. S. (2005). Bárbaros, escravos e civilizados: o público dos museus no Brasil. In: CHAGAS, Mario (Org.). Museus: antropofagia da memória e do patrimônio. Revista do Patrimônio Histórico e Artístico Nacional, No. 31.

Mourão, R. (1994). A nova realidade do Museu. Ouro Preto: MINC-IPHAN, Museu da Inconfidência. (2008). Quando os demônios descem o morro. São Paulo: Casa \& Palavras,

(2010). História e público do Museu da Inconfidência. Entrevistadores: Leandro Benedini Brusadin e Camila de Brito Antonucci Braga. Duração: 63 minutos. Sala da Diretoria do Museu da Inconfidência.

O Museu da Inconfidência (1995). São Paulo: Banco Safra. Vários Colaboradores. Apresentação de Rui Mourão.

SALIBA, E. T. (2007). O passado tem futuro? Anais do Museu Paulista. História e Cultura Material. São Paulo: Universidade de São Paulo, Jan. /dez, v. 15.

Testemunhos dos visitantes do Museu da Inconfidência (1972 a 2009). Livro de Ocorrências. Ouro Preto: Museu da Inconfidência. Arquivo da Secretaria. 
Visitação do Museu da Inconfidência (1944 a 2009). Ouro Preto: Museu da Inconfidência. Arquivo Administrativo - Casa do Pilar. Setor de Difusão e Promoção Cultural.

Artigo recebido em: 25/06/2013. Artigo aprovado em: 27/11/2013. 